\title{
Multi-Index Bi-Criterion Transportation Problem: A Fuzzy Approach
}

\author{
Dr. Samiran Senapati
}

Department of Mathematics, Nabadwip Vidyasagar College, Nadia, West Bengal, India samiransenapati@yahoo.co.in

\begin{abstract}
This paper represents a non linear bi-criterion generalized multi-index transportation problem (BGMTP) is considered. The generalized transportation problem (GTP) arises in many real-life applications. It has the form of a classical transportation problem, with the additional assumption that the quantities of goods change during the transportation process. Here the fuzzy constraints are used in the demand and in the budget. An efficient new solution procedure is developed keeping the budget as the first priority. All efficient time-cost trade-off pairs are obtained. $D_{1}$-distance is calculated to each trade-off pair from the ideal solution. Finally optimum solution is reached by using $D_{1}$-distance.
\end{abstract}

Keywords- Time-cost trade-off pair, $D_{1}$-distance, ideal solution, membership function, priority.

\section{INTRODUCTION}

The cost minimizing classical multi-index transportation problems play important rule in practical problems. The cost minimizing classical multi-index transportation problems have been studied by several authors $[14,15,16$, 17] etc. Some times there may exist emergency situation eg police services, time services, hospital management etc. where time of transportation is of greater importance than cost of transportation. In this situation, it is to be noted that the cost as well as time play prominent roles to obtain the best decision. Here the two aspects (ie cost and time) are conflicting in nature. In general one can not simultaneously minimize both of them. Bi-criterion transportation problem have been studied by several authors $\quad[3,4,8,17,11]$ etc.

There are many business problems, industrial problems, machine assignment problems, routing problems, etc. that have the characteristic in common with generalized transportation problem that have been studied by several authors [1, 2, 4, 5, 9, 10, 14 ] etc.

In real world situation, most of the intimations are imprecise in nature involving vagueness or to say fuzziness. Precise mathematical model are not enough to tackle all practical problems. Fuzzy set theory was developed for solving the imprecise problems in the field of artificial intelligence. To tackle this situation fuzzy set theory are used. In this field area pioneer work came from Bellman and Zadeh [6]. Fuzzy transportation problem have been studied by several authors $[12,18,19,20,21,23,24]$ etc.

The importance of fuzzy generalized multi-index transportation problem is increasing in a great deal but the method for finding time-cost trade-off pair in a bicriterion fuzzy generalized multi-index transportation problem has been paid less attention. In this paper, we have developed a new algorithm to find time-cost trade-off pair of bi-criterion fuzzy generalized multi-index transportation problem. Thereafter an optimum time-cost trade-off pair has been obtained.

\section{Problem Formulation:}

Let there be m-origins, $n$-destinations and $q$ products in a bi-criterion generalized multi-index fuzzy transportation problem.

Let,

$\mathrm{x}_{\mathrm{ijk}}=$ the amount of the k-th type of product transported from the $\mathrm{i}$-th origin to the $\mathrm{j}$-th destination,

$\mathrm{t}_{\mathrm{ijk}}=$ the time of transporting the $\mathrm{k}$-th type of product from the $\mathrm{i}$-th origin to the $\mathrm{j}$-th destination which is independent of amount of commodity transported so long as $\mathrm{x}_{\mathrm{ijk}}>0$,

$\mathrm{r}_{\mathrm{ijk}} \quad=\quad$ the cost involved in transporting per unit of the k-th type of product from the i-th origin to the $\mathrm{j}$-th destination,

$\mathrm{a}_{\mathrm{i}} \quad=\quad$ number of units available at origin $\mathrm{i}$,

$b_{j}=$ number of units required at the destination $\mathrm{j}$,

$\mathrm{c}_{\mathrm{k}} \quad=\quad$ requirements of the number of units of the k-th type of product and

$\mathrm{d}_{\mathrm{ijk}}^{1}, \mathrm{~d}_{\mathrm{ijk}}^{2}=$ 
generalized multi-index transportation problem (GMTP).

Then the cost minimizing fuzzy GMTP can be formulated as follows:

$$
P_{1}: \text { Find } \mathrm{x}_{\mathrm{ijk}}(\geq 0) ;(1 \leq \mathrm{i} \leq \mathrm{m}, \quad 1 \leq \mathrm{j} \leq \mathrm{n}, 1 \leq \mathrm{k} \leq \mathrm{q})
$$

subject to the constraints,

$$
\begin{aligned}
& \sum_{j=1}^{n} \sum_{k=1}^{q} d_{i j k}^{1} x_{i j k} & \leq \mathrm{a}_{\mathrm{i}} ; \quad 1 \leq \mathrm{i} \leq \mathrm{m}, \\
b_{j}^{*} \leqq & \sum_{\mathrm{i}=1}^{\mathrm{m}} \sum_{\mathrm{k}=1}^{\mathrm{q}} \mathrm{x}_{\mathrm{ijk}} & \leq \mathrm{b}_{\mathrm{j}} ; 1 \leq \mathrm{j} \leq \mathrm{n}_{\mathrm{g}} \\
& \sum_{\mathrm{i}=1}^{\mathrm{m}} \sum_{\mathrm{j}=1}^{\mathrm{n}} \mathrm{d}_{\mathrm{ijk}}^{2} x_{i j k} & \leq \mathrm{c}_{\mathrm{k}} ; \quad 1 \leq k \leq q_{\mathrm{is}}^{\text {(ii) }} \\
\text { and } & \sum_{\mathrm{i}=1}^{\mathrm{m}} \sum_{\mathrm{j}=1}^{\mathrm{n}} \sum_{\mathrm{k}=1}^{\mathrm{q}} \mathrm{r}_{\mathrm{ijk}} x_{i j k} & \leq \mathrm{Z}_{1}
\end{aligned}
$$

Some times there may arise emergency situation, eg, hospital managements, fire services, police services etc., where the time of transportation is of greater importance than that of cost. Then time minimizing transportation problem arises. The time minimizing transportation problem can be written as:

$$
\mathrm{P}^{1}: \operatorname{Min} \mathrm{T}=\operatorname{Max}_{\substack{1 \leq \mathrm{i} \leq \mathrm{m} \\ 1 \leq \mathrm{j} \leq \mathrm{n} \\ 1 \leq \mathrm{k} \leq \mathrm{q}}}\left\{\mathrm{t}_{\mathrm{ijk}}: \mathrm{x}_{\mathrm{ijk}}>0\right\}
$$

Subject to the constraints (1).

Combining the problem $\mathrm{P}_{1}$ and $\mathrm{P}^{1}$, the fuzzy BGMTP appears as:

$$
\mu D_{j}(x)=\left\{\begin{array}{cc}
\frac{\sum_{i=1}^{m} \sum_{k=1}^{q} x_{i j k}-\left(B_{j}^{*}-\Delta b_{j}\right)}{\Delta b_{j}} & \text {;if } \mathrm{B}_{\mathrm{j}}^{*}-\Delta b_{j} \leq \sum_{i=1}^{m} \sum_{k=1}^{q} x_{i j k}<B_{j}^{*} ; \\
\frac{\left(B_{j}^{*}+\Delta b_{j}\right)-\sum_{i=1}^{m} \sum_{k=1}^{q} x_{i j k}}{\Delta b_{j}} & ; \text { if } \mathrm{B}_{\mathrm{j}}^{*}<\sum_{i=1}^{m} \sum_{k=1}^{q} x_{i j k} \leq B_{j}^{*}+\Delta b_{j} ; \\
0 & ; \text { if } \sum_{\mathrm{i}=1}^{\mathrm{m}} \sum_{\mathrm{k}=1}^{\mathrm{q}} \mathrm{x}_{\mathrm{ijk}}>B_{j}^{*}+\Delta b_{j} \text { and } \\
\sum_{\mathrm{i}=1}^{\mathrm{m}} \sum_{\mathrm{k}=1}^{\mathrm{q}} \mathrm{x}_{\mathrm{ijk}}<B_{j}^{*}-\Delta b_{j}
\end{array}\right.
$$

where $b_{j}^{*}$ and $b_{j}$ are the lower tolerance limit and upper tolerance limit respectively of the demand $\mathrm{j}(1 \square \mathrm{j} \square \mathrm{n}$ ) and subject to the constraints (1).

Difference between Classical Multi-index Transportation Problem (MTP) and Generalized Multiindex Transportation Problem (GMTP):

classical MTP and GMTP which are given below:

(i) The rank of the co-efficient matrix $\left[\mathrm{x}_{\mathrm{ijk}}\right]_{\mathrm{m}} \times \mathrm{n} \times \mathrm{q}$ is in constraints are in general independent.

(ii) In GMTP the value of $x_{i j k}$ may not be integer, though it is integer in classical MTP.

(iii) The activity vector in GMTP is

$$
P_{i j k}=d_{i j k}^{1} e_{i}+e_{m+j}+d_{i j k}^{2} e_{m+n+k}
$$

Whereas in classical MTP it is

$$
P_{i j k}=e_{i}+e_{m+j}+e_{m+n+k} .
$$

(iv) In GMTP it need not be true that cells corresponding to a basic solution form a tree. Or in other words vectors in the loop are linearly independent. But in classical MTP vectors in the loop are linearly dependent.

The problem consists of two parts,

$\mathrm{P}_{1}$ : the problem of solving the fuzzy GMTP

$\mathrm{P}^{1}$ : the problem of minimizing the time.

To solve the problem $P$, the following technique is used.

The triangular membership function for the fuzzy demand constraints are 
$\Delta b_{j}=\frac{b_{j}-b_{j}^{*}}{2}, B_{j}^{*}=\frac{b_{j}+b_{j}^{*}}{2}$

The linear membership function of the fuzzy budget goal can be written as:

$$
\mu R(x)= \begin{cases}1 \quad \text { if } \sum_{\mathrm{i}=1}^{\mathrm{m}} \sum_{\mathrm{j}=1}^{\mathrm{n}} \sum_{\mathrm{k}=1}^{\mathrm{q}} \mathrm{r}_{\mathrm{ijk}} x_{i j k} \leq Z_{1}, \\ \frac{\mathrm{Z}^{*}-\sum_{i=1}^{m} \sum_{j}^{n} \sum_{k=1} r_{i j k} x_{i j k}}{\Delta Z} ; \text { if } \mathrm{Z}_{1}<\sum_{i=1}^{m} \sum_{j=1}^{n} \sum_{k=1}^{q} r_{i j k} x_{i j k}<Z^{*}, \\ 0 \quad ; \text { if } \sum_{i=1}^{m} \sum_{j=1}^{n} \sum_{k=1}^{q} r_{i j k} x_{i j k} \geq Z^{*}\end{cases}
$$

Where $Z^{*}$ is the upper tolerance limit of the budget goal and $\Delta Z=Z^{*}-Z_{1}$.

\section{SOLUTION PROCEDURE}

The fuzzy programming model of problem $\mathrm{P}_{1}$ is equivalent to the following linear programming problem as:

$\operatorname{Max} \lambda$

subject to the constraints

$$
\begin{aligned}
& \sum_{j=1}^{n} \sum_{k=1}^{q} d_{i j k}^{1} x_{i j k} \leq \mathrm{a}_{\mathrm{i}} \quad ; \quad 1 \leq \mathrm{i} \leq \mathrm{m}, \\
& \sum_{\mathrm{i}=1}^{\mathrm{m}} \sum_{\mathrm{j}=1}^{\mathrm{n}} \mathrm{d}_{\mathrm{ijk}}^{2} x_{i j k} \leq \mathrm{c}_{\mathrm{k}} \quad ; \quad 1 \leq k \leq q, \\
& \lambda \leq \mu D_{j}(x) \quad ; \quad 1 \leq \mathrm{j} \leq \mathrm{n}, \\
& \lambda \leq \mu \mathrm{R}(\mathrm{x}), \\
& \lambda=\min \left[1 \leq \mathrm{j} \leq \mathrm{n}, \mu D_{j}(\mathrm{x}), \mu \mathrm{R}(\mathrm{x})\right]
\end{aligned}
$$

$$
\text { and } \lambda \in[0,1]
$$

After solving the problem the optimum solution $X_{1}^{*}$ and the corresponding optimum cost $Z_{1}^{*}$ at the first iteration are obtained. Next the problem $\mathrm{P}^{1}$ is solved for minimizing the time.

Let $T_{1}^{*}=\operatorname{Min}\left[\operatorname{Max}_{\substack{1 \leq i \leq m \\ 1 \leq j \leq n \\ 1 \leq k \leq q}}\left\{t_{i j k}: x_{i j k}>0, x_{i j k} \in X_{1}^{*}\right\}\right]$

subject to the constraints (1)

So, for the first iteration the time-cost trade-off pair is $\left(Z_{1}^{*}, T_{1}^{*}\right)$. Using re-optimizing technique and replacing $\quad Z_{\mathrm{r}} \quad$ by $\quad \mathrm{Z}_{\mathrm{r}+1}, \quad\left(\begin{array}{llllll}1 & \square & \mathrm{r} & \square & \mathrm{h}-1) & \text { where }\end{array}\right.$ $Z_{r}<Z_{r+1}<\mathrm{Z}^{*} ; \forall \mathrm{r}$ and $1 \square \mathrm{r} \square \mathrm{h}-1$. All efficient $\left(Z_{1}^{*}, T_{1}^{*}\right),\left(Z_{2}^{*}, T_{2}^{*}\right)$ $\left(Z_{r}^{*}, T_{r}^{*}\right)$ $\left(Z_{h}^{*}, T_{h}^{*}\right)$ (say)

where $Z_{1}^{*}<Z_{2}^{*}<\ldots \ldots . .<Z_{r}^{*}<\ldots \ldots \ldots .<Z_{h}^{*}$

and $T_{1}^{*}>T_{2}^{*}>\ldots \ldots . .>T_{r}^{*}>\ldots \ldots .>T_{h}^{*}$

The pair $\left(Z_{1}^{*}, T_{h}^{*}\right)$ is termed as the ideal solution.

Let,

$$
\left.\begin{array}{rl}
d_{r} & =Z_{r}^{*}-Z_{1}^{*} \\
\mathrm{~d}_{\mathrm{h}+\mathrm{r}} & =T_{r}^{*}-T_{h}^{*}
\end{array}\right\}
$$


So,

$$
\begin{aligned}
\left(\mathrm{D}_{1}\right)_{\mathrm{opt}} & =\operatorname{Min}_{1 \leq \mathrm{r} \leq \mathrm{h}}\left(\mathrm{D}_{1}\right)_{\mathrm{r}} \\
= & \operatorname{Min}_{1 \leq r \leq h}\left(d_{r}+d_{h+r}\right) \\
= & d_{s}+d_{h+s} \quad \text { (say) } \\
= & \left(\mathrm{D}_{1}\right)_{\mathrm{s}}
\end{aligned}
$$

Since equal priority to cost as well as time is given, so $\left(Z_{s}^{*}, T_{s}^{*}\right)$ attains the optimum trade-off pair.

\section{The Algorithm:}

Step - 1: Set $b=1$, where $b$ is the number of iteration.

$$
\begin{array}{ll}
\text { Step - 2: } & \text { Solve problem } \mathrm{P}_{1} \text {. Let } Z_{1}^{*} \text { be the } \\
& \text { optimum total cost corresponding to the } \\
& \text { optimum solution } X_{1}^{*} . \\
\text { Step - 3: } \quad & \text { Find } T_{1}^{*} \\
& \text { where, } \\
& T_{1}^{*}=\underset{\substack{1 \leq i \leq m \\
1 \leq \mathbf{j} \leq n \\
1 \leq k \leq q}}{\operatorname{Max}\left\{t_{i j k}: x_{i j k}>0 \text { according to } \mathrm{X}_{1}^{*}\right\}}
\end{array}
$$

Then $\left(Z_{1}^{*}, T_{1}^{*}\right)$ is called time-cost tradeoff pair at the first iteration.

Step - 4: Define

$$
r_{i j k}^{b+1}=\left\{\begin{array}{llc}
M & \text { if } & \mathrm{t}_{\mathrm{ijk}} \geq T_{b}^{*} \\
r_{i j k} & \text { if } & \mathrm{t}_{\mathrm{ijk}}<T_{b}^{*}
\end{array}\right.
$$

Step - 7:

Step-8: $\quad$ Let after the h-th step the algorithm terminates, ie, $Z_{h+1}^{*} \geq M$, then the complete set of time-cost trade-off pairs,

$$
\left(Z_{1}^{*}, T_{1}^{*}\right),\left(Z_{2}^{*}, T_{2}^{*}\right)
$$

cost trade-off pair is $\left(Z_{b+1}^{*}, T_{b+1}^{*}\right)$.

Obviously $Z_{b+1}^{*}>Z_{b}^{*}$ and $T_{b+1}^{*}<T_{b}^{*}$.

Set $b=b+1$ and go to step 4 . 


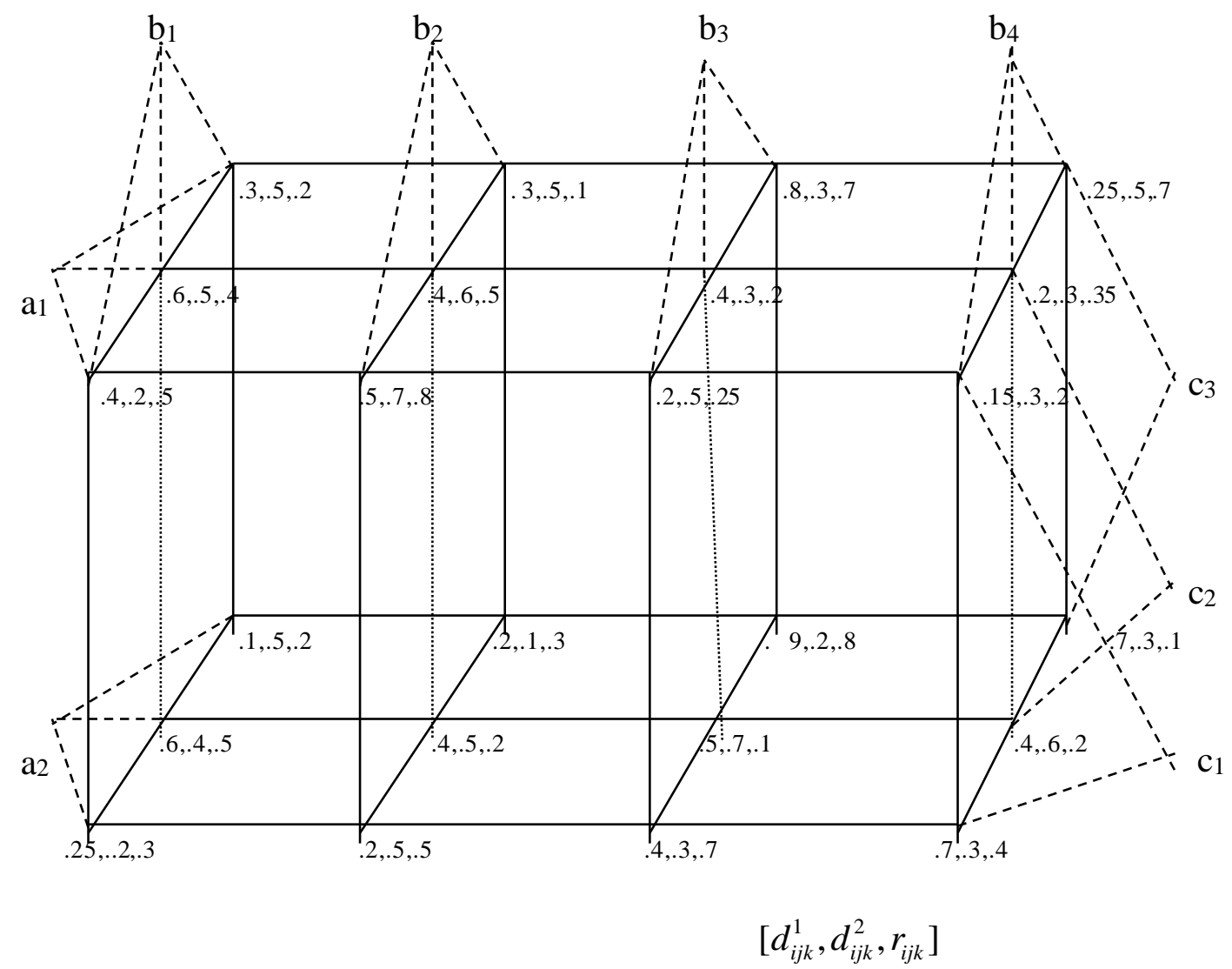

Figure - 2

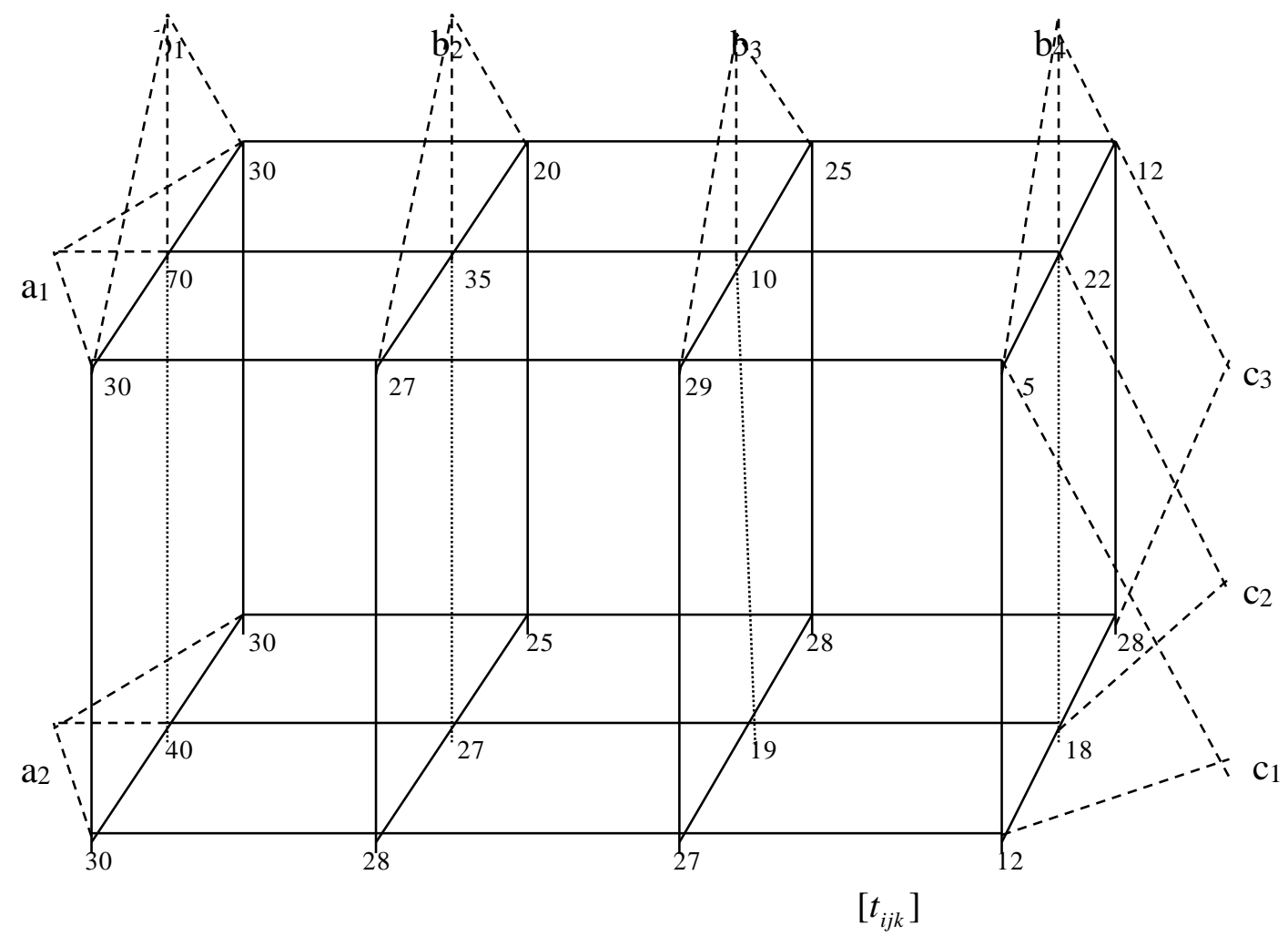


Four time-cost trade-off pairs $(1250,70),(1275,40),(1300,35),(1310,30)$ are obtained. The result shows that the ideal solution is $(1250,30)$. The $\left(\mathrm{D}_{1}\right)$ distance of the trade-off pairs from the ideal solution is presented in the Table - 2.

\section{Table -2}

\begin{tabular}{|c|c|c|c|c|}
\hline $\begin{array}{l}\text { Trade-off } \\
\text { pairs }\end{array}$ & $\begin{array}{l}\text { Ideal } \\
\text { Solution }\end{array}$ & $\begin{array}{l}\text { Distance }\left(D_{1}\right)_{\mathrm{r}} \text { between ideal } \\
\text { solution and the trade-off pair }\end{array}$ & $\left(\mathrm{D}_{1}\right)_{\mathrm{opt}}$ & $\begin{array}{l}\text { Optimum time-cost } \\
\text { trade-off pair }\end{array}$ \\
\hline$(1250,70)$ & \multirow{4}{*}{$(1250,30)$} & 40 & \multirow{4}{*}{35} & \multirow{4}{*}{$(1275,40)$} \\
\hline$(1275,40)$ & & 35 & & \\
\hline$(1300,35)$ & & 55 & & \\
\hline$(1310,30)$ & & 60 & & \\
\hline
\end{tabular}

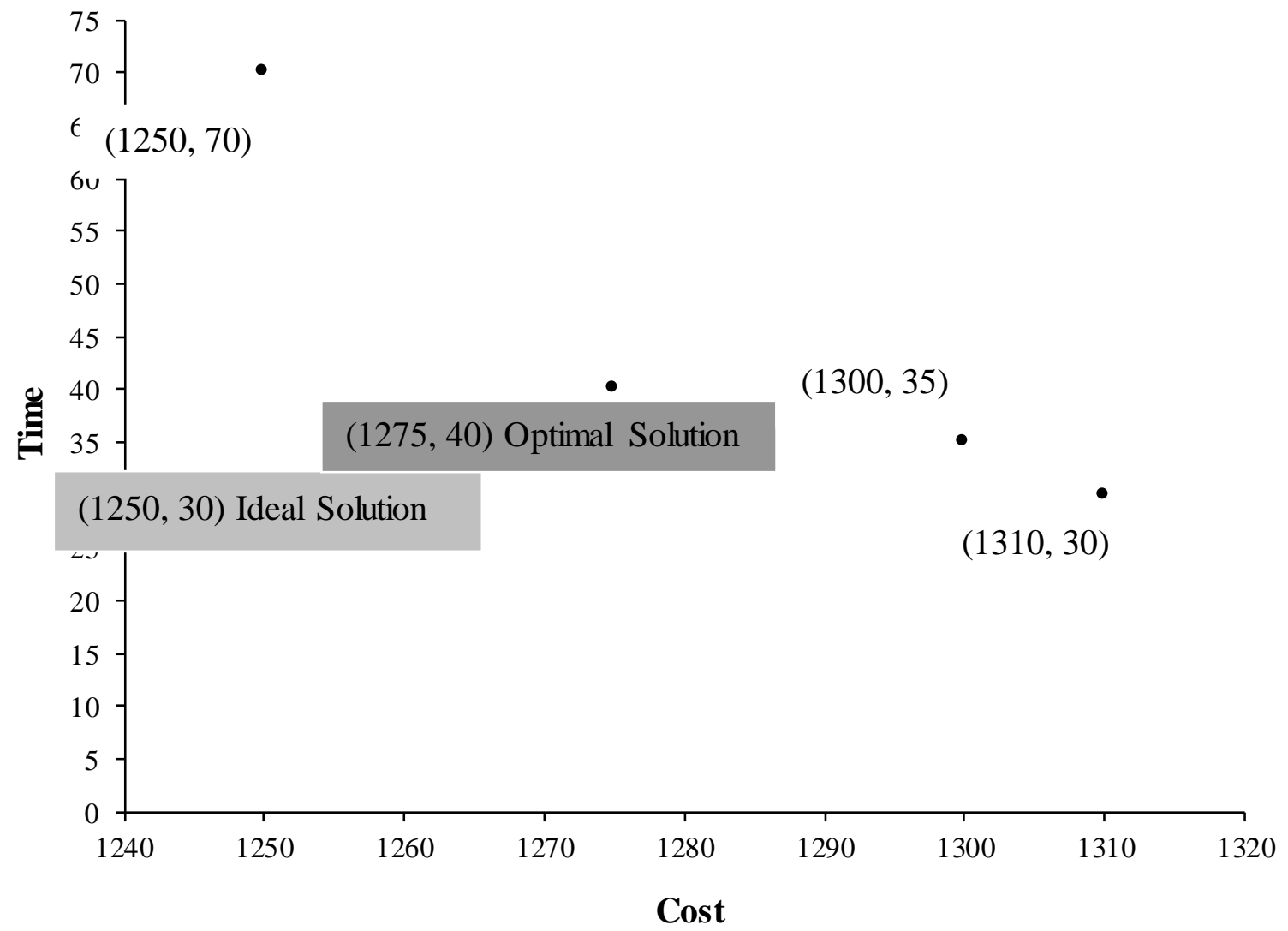

Time - Cost Graph

So the optimum time-cost trade-off pair is $(1275,40)$.

\section{REFERENCES}

[1] Bala, E., Ivanescu, P. L. (1964): "On the generalized transportation problem". Management Science, Vol. 11, p. 188 - 202.

[2] Balachandran, V. (1976): “An integer generalized Transportation model for optimal job assignment in computer networks, Operation Research, Vol. 24, p. $742-759$.
[3] Basu, M., Pal, B. B., Kundu, A. (1993): "An algorithm for the optimum time cost trade-off in three dimensional transportation problem", Optimization, Vol. $28, \quad$ p. $171-185$.

[4] Basu, M., Acharya Debiprasad (2000) : "An algorithm for the optimum time cost trade-off in generalized solid transportation problem, International Journal of Management Science, Vol. 16, No. 3, p. 237 - 250. 
[5] Basu, M., Acharya Debiprasad (2002): "On Quadratic fractional generalized Solid bi-criterion transportation problem", Journal of Applied Mathematics and Computing, Vol. 10 No. 1 - 2, p. 131 - 143.

[6] Bellman, R. E. and Zadeh, L. A., (1970): 'Decision making in a Fuzzy Environment', Management Science, Vol. 17, B141 - B164.

[7] Charnes, A., Cooper, W. W. (1957), "Management models and industrial application of linear programming”, Management Science, Vol. 4, p. 38 91.

[8] Cohon, J. L., (1978), "Multiobjective programming and planning, Academic Press,

[9] Elseman, E. (1964) : "The generalized stepping stone method to the machine loading model, Management, Vol. 11, p. 154 - 178.

[10] Ferguson, A. R., Dantzig, G. B. (1956): The allocation of aircraft to routes. An example of linear programming under uncertain demand". Management Science, Vol. 6, p. 45 - 73.

[11] Fisher, M. L. (1981): "A generalized assignment heuristic for vehicle routing networks, Vol. 11, p. 109 $-124$.

[12] Freeling, A. M. S. (1980): Fuzzy Sets and Decision Analysis, IEEE Transaction on Systems. Man and Cybernetics, Vol. 10, p. 341 - 354.

[13] Gunginger, W. (1976): "An algorithm for the solution of multi-index transportation problem. M. Roubens (Ed.) Advs In Ops. Res. Proceedings of Euro., Vol. 11, p. $229-295$.

[14] Hadley, G. (1987): Linear Programming, Narosa Publishing House, New Delhi.

[15] Halley, K. B. (1962) : The solid transportation problem", Ops. Res. Vol. 10, p. 448 - 463.

[16] Halley, K. B. (1963): "The existence of solution to the multi-index problem”, Ops. Res. Quart., Vol. 16, p. $471-474$.

[17] Haman, E. L. (1982): "Contrasting Fuzzy goal programming and Fuzzy multicriteria Programming", Decision Science, Vol. 13, p. 337 - 339.

[18] Hamen, P. L. (1969): "Time minimizing transportation problem”, Nav. Res. Logis. Quart., Vol. 16, p. 345 357.

[19] L. A. Zadeh, (1965): 'Fuzzy Sets', Information Control, Vol. 8, p. 338 - 353.

[20] Luhandjula, M. K., (1984): 'Fuzzy approaches for Multiple Objective Linear Fractional Optimization, "Fuzzy Sets and System, Vol. 13, p. 11 - 23.

[21] Negoita, C. V. and Rolescu, D. A., (1977) : 'On Fuzzy
Optimization' Kybernetes, Vol. 6, p. 193 - 196.

[22] Negoita, C. V., (1981): 'The Current Interest in Fuzzy optimization', 'Fuzzy Sets and Systems', Vol. 6 (1981), p. $261-269$.

[23] Negoita, C. V., Sularia, M., (1976), 'On Fuzzy Mathematical Programming and Tolerances in planning', Economic Computer and Economic Cybernetic Studies and Researches, Vol. 8, p. 3 - 15.

[24] Oheigeartaigh, M. (1982): 'A Fuzzy Transportation Algorithm Fuzzy Sets and Systems, Vol. 8, p. 235 243. 